\title{
EDUCAÇÃO PERMANENTE E O CÍRCULO DE CULTURA FREIREANO: DIÁLOGOS COM IDOSOS
}

DOI: 10.48075/RI.V24I2.26624

Daniel de Aguiar Pereira ${ }^{1}$ Mônica de Ávila Todaro

Meire Cachioni ${ }^{3}$

RESUMO: O objetivo deste estudo foi caracterizar o perfil dos idosos participantes da oficina "Diálogos com quem gosta de ler e escrever" e analisar suas produções escritas para averiguar os significados e os sentimentos atribuídos à prática educativa, inspirada no Círculo de Cultura freireano. Tratou-se de um estudo de abordagem quanti-qualitativa com 66 idosos, escolarizados, saudáveis, que frequentaram a Universidade Aberta à Terceira Idade da Escola de Artes, Ciências e Humanidades da Universidade de São Paulo. Os dados quantitativos foram descritos por meio da estatística inferencial, e os qualitativos foram tratados por meio da análise de conteúdo proposta por Bardin (2011). Os resultados revelaram que a oficina trouxe mudanças positivas, possibilitando novos sentidos e sentimentos de bem-estar nos idosos.

Palavras-chave: Educação permanente; Círculo de Cultura; idosos.

\section{PERMANENT EDUCATION AND THE FREIREAN CULTURE CIRCLE: DIALOGS WITH THE ELDERLY}

ABSTRACT: The objective of this study was to characterize the profile of the elderly participants in the workshop "Dialogues with those who like to read and write" and to analyze their written productions to ascertain the meanings and feelings attributed to the educational practice, inspired by the Freirean Culture Circle. It was a study of quantitative-qualitative approach with 66 elderly, educated, healthy, who attended the Universidade Aberta for the Third Age of the School of Arts, Sciences and Humanities of the University of São Paulo. Quantitative data were described using inferential statistics, and qualitative data were treated using the content analysis proposed by Bardin (2011). The results revealed that the workshop brought positive changes, enabling new meanings and feelings of wellbeing in the elderly.

Key words: Permanent education; Culture Circle; elderly.

1 Doutor em Gerontologia pela Universidade Estadual de Campinas (UNICAMP). E-mail danielpaguiar@hotmail.com

${ }^{2}$ Professora Adjunta da Universidade Federal de São João del-Rei (UFSJ). E-mail mavilatodaro@ufsj.edu.br

${ }^{3}$ Professora Associada da Escola de Artes, Ciências e Humanidades (Each-USP). E-mail meirec@usp.br 


\section{INTRODUÇÃO}

Pensar em uma educação para e com o idoso tem se tornado um desafio, dado o fenômeno do envelhecimento populacional. Aliado a esse desafio, soma-se a proposta de pensar práticas de educação que sejam, ao mesmo tempo, problematizadoras, permanentes e transformadoras, e que sejam capazes de oportunizar as ferramentas necessárias aos sujeitos idosos na sua participação e intervenção nas tomadas de decisões referentes às suas próprias vidas e à sua vida no coletivo. Frente ao que se coloca, este estudo pretende caracterizar o perfil dos idosos que procuram oficinas em espaços educativos não-formais e compreender quais sentidos e sentimentos os Círculos de Cultura, de inspiração freireana, fazem emergir.

Compartilhar saberes com os atores do processo educativo é o objetivo primeiro de uma proposta de educação permanente que pretenda gerar uma relação de ensino e de aprendizagem transformadora, humanizadora e capaz de mediar uma tomada de consciência ao idoso da complexidade do momento mundial atual. É no Círculo de Cultura que o sujeito se percebe construtor de seu conhecimento e sente seus saberes valorizados, posicionandose como um sujeito capaz de promover mudanças.

Desse modo, o conceito de educação permanente adotado considera o idoso como sujeito vivo e atuante em seu tempo, em seu presente, estando no mundo, sendo participante em sua comunidade e em sua vida, de forma autônoma, decidida, independente e inacabada. Como afirma Freire (1987, p. 64):

É na inconclusão do ser, que se sabe como tal, que se funda a educação como processo permanente. Mulheres e homens se tornam educáveis na medida em que se reconhecem inacabados. Não foi a educação que fez mulheres e homens educáveis, mas a consciência de sua inconclusão é que gerou educabilidade.

A nenhum sujeito da educação aplica-se tão bem quanto aos idosos a noção de que o ser humano é agente do seu próprio crescimento e da transformação da realidade (CACHIONI, 2002). Para que possa afetar positivamente os idosos, a relação ensino e aprendizagem deve centrar-se em um processo permanente de busca por ser mais, expressão freireana que traduz o potencial de ir além e transcender a si mesmo. 
Modificar as abordagens, os objetivos, os conteúdos e os métodos de acordo com as necessidades dos idosos e da sociedade que envelhece deve ser a proposta de educação voltada a idosos, inserida em uma perspectiva de educação permanente, que se dê ao longo da vida e que considere o sujeito como agente de sua própria educação na interrelação com outros sujeitos em um movimento dialético eu-tu-nós. É com essa proposta que algumas instituições não governamentais, instituições privadas e universidades abertas à terceira idade têm existido e atendido a essa nova e crescente demanda de educação, com uma programação baseada em três eixos: i. atividade; ii. autonomia e independência; e iii. participação e integração. Assim, tem demonstrado ser lócus de ocorrência e de respostas adaptativas dos idosos e do envelhecimento bem-sucedido de outros sujeitos participantes (CACHIONI; NERI, 2008), o que possibilita "[...] olhar o idoso a partir de perspectivas de atividade, participação, reinvindicação, autodeterminação e envolvimento com a vida" (CACHIONI, 2002).

Assumir abordagens de ensino e de aprendizagem mais horizontais e problematizadoras, tal qual propôs Freire, a partir dos anos de 1960, nos Círculos de Cultura, parece contribuir para a construção de processos de libertação e de reflexão crítica quando se trata de uma ação educativa voltada às pessoas idosas. Dessa forma, o educador, comprometido com a construção de uma abordagem de ensino e de aprendizagem políticotransformadora e permanente, constrói a sua docência voltada à autonomia do educando, valorizando e respeitando a sua cultura e o seu acervo de conhecimentos empíricos junto a sua individualidade e a sua intencionalidade para o aprender (FREIRE, 1997).

Neste artigo, portanto, são apresentados os resultados da oficina "Diálogos com quem gosta de ler e escrever", prática de educação permanente para idosos, oportunizada pela Universidade Aberta à Terceira Idade da Escola de Artes, Ciências e Humanidades da Universidade de São Paulo (EACH/USP). Para tanto, a pesquisa pautou-se nas seguintes questões: Qual perfil socioeconômico, de escolarização, de idade e étnico dos praticantes da EACH/USP que se matricularam na "Oficina: Diálogos com quem gosta de ler e escrever"?; Quais as relações de escolaridade e renda mensal com o perfil neuropsicológico geral (pré e pós teste) dos participantes dos dois grupos da oficina "Diálogos com quem gosta de ler e escrever", Grupo Teste (GT) e Grupo Controle (GC)?; e Qual o perfil neuropsicológico geral de 
ingresso (pré) e egresso (pós) em uma ação educativa inspirada no Círculo de Cultura freireano?

As respostas encontradas serviram para caracterizar os idosos que frequentaram a oficina "Diálogos com quem gosta de ler e escrever", segundo variáveis socioeconômicas, de escolaridade e de etnia; relacionar as pontuações do teste psicométrico: Instrumento de Avaliação Neuropsicológica Breve (NEUPSILIN) com escolaridade, renda, idade e etnia; avaliar o teste psicométrico antes e depois da aplicação das oficinas; comparar o resultado do teste entre grupos; e analisar seus discursos.

Dessa forma, foi possível sustentar a ideia de que a inserção de idosos escolarizados, ou não, em programas não formais de educação permanente, indica ser essencial para o bemestar social, físico, emocional e para o desenvolvimento pessoal do idoso (CACHIONI, $1998,2005)$; bem como defender que os pressupostos de uma pedagogia freireana proporcionam mudanças positivas na vida desses sujeitos ao possibilitar ao idoso problematizar temas atuais e viver uma velhice bem-sucedida e ativa.

\section{MÉTODO}

A pesquisa assinala-se como um estudo de cunho quanti-qualitativo, de natureza descritiva inferencial, desenvolvida no período de agosto de 2017 a junho de 2018, com a finalidade de caracterizar o perfil dos idosos que procuram educação na velhice e compreender quais os significados e os sentidos que emergem nos Círculos de Cultura freireano em seu ato educativo. Foi realizada na Universidade Aberta à Terceira Idade da $\mathrm{EACH} /$ USP na oficina "Diálogos com quem gosta de ler e escrever".

Os participantes idosos foram selecionados para a composição dos grupos teste e de controle desta pesquisa, de acordo com a sua livre escolha para matricular-se na oficina. Eles foram previamente avisados dos objetivos dos encontros, da pesquisa investigativa, e tiveram liberdade de escolha para participar ou não da pesquisa. Os idosos foram aleatorizados perante a sua disponibilidade de dia e horário para participação nas propostas. O GT aconteceu às segundas-feiras, das 14 horas às 16 horas, e o GC, às quartas-feiras, das 14 horas às 16 horas. A oficina aconteceu separadamente ao longo de dois semestres; 1a Chamada 07/08/2017 até 04/12/2017; e 2ạ Chamada - 05/03/2018 até 20/06/2018. 
Todos os 66 idosos matriculados na oficina participaram da pesquisa; entretanto, apenas os 44 idosos que frequentaram o GT da oficina produziram um texto, intitulado "Minha experiência na Oficina", os quais destacaram os significados e os sentidos que a educação permanente ganha no processo de envelhecer e na velhice. Os idosos eram predominantemente mulheres, brancas e de classe média, com o mínimo de 4 anos de escolaridade.

O procedimento de chamada (convite) contou com a entrega de um folder explicativo com a seguinte proposta da oficina: As práticas sociais de leitura e de escrita estão presentes na vida cotidiana de praticamente toda a sociedade. Ler um livro, pegar o ônibus correto para casa ou para ir a um determinado lugar, orientar-se pelas placas de trânsito, ler a bula de um remédio, compor uma música com os amigos, ler o resumo das novelas na revista, fazer uma lista de compras etc. Todas essas atividades constituem formas de utilização social da leitura e da escrita; dessa forma, são práticas de letramento.

Para a coleta de dados, foram utilizados os seguintes instrumentos: 1) Ficha de caracterização sociodemográfica do idoso, que teve por objetivo levantar o perfil dos sujeitos envolvidos na pesquisa, no que se refere aos seus dados pessoais, tais como: idade, gênero, escolaridade, ocupação e renda; e 2) Instrumento de Avaliação Neuropsicológica Breve NEUPSILIN, com o objetivo de fornecer um perfil neuropsicológico breve, quantitativo e qualitativo, mediante identificação de preservação ou prejuízo das habilidades neuropsicológicas.

O NEUPSILIN é um instrumento de avaliação resultante de um extenso trabalho de pesquisa em Neuropsicologia Clínica e Cognitiva, embasado em várias áreas do conhecimento, tais como: Psicologia Cognitiva e Comportamental, Psicolinguística, Psicometria, Neurologia e Fonoaudiologia. De aplicação individual e com tempo estimado de 30 a 50 minutos, o NEUPSILIN considera a descrição sistemática das habilidades cognitivas individuais como um ponto-chave para que os profissionais da Saúde e da Educação possam oferecer suporte e estratégias de intervenção às pessoas que apresentam déficits cognitivos ou neuropsicológicos. O NEUPSILIN é composto por tarefas curtas, de resolução acessível e tem um tempo de aplicação reduzido. Por ser um instrumento breve, aplica-se tanto ao contexto clínico, público ou privado quanto ao contexto hospitalar, podendo até mesmo ser aplicado no próprio leito de um paciente, dada a facilidade de manuseio do material. Além disso, 
contêm 32 subtestes que avaliam oito funções neuropsicológicas, sendo elas: Orientação têmporo-espacial; Atenção concentrada; Percepção visual (de tamanho, campos visuais e faces); Habilidades aritméticas (calculias simples); Linguagem oral e escrita (níveis da palavra e da sentença); Memória verbal (de trabalho, episódica, semântica, prospectiva) e visual (reconhecimento); Praxias (ideomotora, construtiva e reflexiva); e Funções executivas (resolução de problemas e fluência verbal fonêmica).

Para esta pesquisa, no ato da investigação e da aplicação do NEUPSILIN, deu-se ênfase às pontuações dos seguintes subdomínios: linguagem, memória, funções executivas e tempo de aplicação do teste. Essa decisão deu-se devido à grande ocorrência de queixas relacionadas a esses subdomínios da cognição e aos complexos subprocessos envolvidos em cada uma dessas funções. As respostas dadas pelos idosos foram anotadas no próprio protocolo para a avaliação dos resultados.

Os Círculos de Cultura da oficina "Diálogos com quem gosta de ler e escrever" aconteceram em uma proposta de 40 horas de encontros, realizados duas vezes por semana, com duração de uma hora e meia cada. A ficha de caraterização sociodemográfica foi aplicada anteriormente ao início das propostas de intervenção educativa, com o objetivo de caracterizar os idosos frequentadores das oficinas. O instrumento NEUPSILIN funcionou como pré-teste e pós-teste das intervenções, oferecendo subsídios para traçar o perfil das habilidades neuropsicológicas dos participantes idosos ao iniciar e concluir a oficina.

Já os dados para a análise qualitativa foram coletados por meio de uma produção textual intitulada "Minha Experiência na Oficina Diálogos", contendo os significados e os sentimentos (sentidos) que envolvem o processo de educação e aprendizagem com os Círculos de Cultura. Em razão da robustez do objeto de estudo, categorias foram definidas para a análise dos significados e sentimentos suscitados nos Círculos de Cultura: 1) significado dos Círculos de Cultura; e 2) sentimentos que emergem ao estarem inseridos em um processo de educação permanente.

A análise dos dados quantitativos foi realizada por meio do Software SPSS 22.0. Adotou-se uma abordagem de estatística descritiva e inferencial, e utilizou-se a frequência e o percentual como medidas descritivas para as variáveis categóricas. Para as variáveis numéricas, inicialmente foi verificada a normalidade dos dados por meio do teste de Kolmogorov-Smirnov. Como os dados não apresentaram distribuição normal, foram utilizadas 
mediana (Md) e quartis (Q1; Q3) para a caracterização dos resultados. Na estatística inferencial, o teste do Qui-quadrado foi aplicado para comparar as proporções de idosos pertencentes ao GC e GT em função do perfil sociodemográfico. Na comparação do perfil de memória, linguagem e funções executivas pré e pós-teste e quanto aos grupos (GC e GT), foi utilizado o teste de Wilcoxon e "U" de Mann-Whitney. A correlação entre o perfil de memória, linguagem e funções executivas foi verificada por meio do coeficiente de Spearman. Considerou-se um nível de significância de $p<0,05$.

Os dados qualitativos foram sistematizados em duas categorias de análise distintas, em busca de compreender o significado das produções que permitissem a inferência de conhecimentos relativos aos processos educativos; assim, utilizou-se a análise de conteúdo proposta por Bardin (2011). Conforme a autora, a análise de conteúdo é um conjunto de técnicas de análise das comunicações, que utiliza procedimentos sistemáticos e objetivos de descrição do conteúdo das mensagens. A autora completa a descrição afirmando que a intenção da análise do conteúdo é a inferência de conhecimentos relativos às condições de produção (ou, eventualmente, de recepção), inferência que recorre a indicadores (quantitativos ou não).

Dessa forma, as categorias foram definidas e classificadas de acordo com os conteúdos presentes na escrita dos idosos. As categorias analíticas permitiram verificar a frequência, a identificação e a extração de conteúdos significativos ao objetivo deste estudo. Por fim, as interpretações e os resultados ilustram a dimensão que a educação, em uma perspectiva freireana de Círculo de Cultura, trouxe para os participantes.

\section{RESULTADOS QUANTITATIVOS}

A partir da Tabela 1, nota-se que parte dos idosos participantes é do sexo feminino $(70,83)$, casado $(30,2 \%)$, com idade entre 60 e 70 anos $(71,9 \%)$, renda mensal de um a dois salários-mínimos $(46,0 \%)$, da raça branca $(54,0 \%)$, e que mora com uma ou duas pessoas $(43,5 \%)$. Observou-se também que grande parte dos idosos relatou ter 15 anos ou mais de estudo $(57,1 \%)$ e que nunca teve reprovação escolar (60,3\%). Esse é um dado discrepante da realidade geral brasileira, uma vez que o Instituto Brasileiro de Geografia e Estatística (IBGE), o Instituto Nacional de Estudos e Pesquisas Educacionais Anísio Teixeira (INEP), as pesquisas 
do Ministério da Educação, os índices do Instituto Paulo Montenegro (INAF) e a Pesquisa Nacional por Amostra de Domicílio (PNAD) - contínua/2017 ainda apontam para os altos índices de analfabetismo funcional na vida adulta.

Tabela 1 - Perfil sociodemográfico dos idosos

\begin{tabular}{|c|c|c|}
\hline VARIÁVEIS & $f$ & $\%$ \\
\hline \multicolumn{3}{|l|}{ Sexo } \\
\hline Masculino & 19 & 29,7 \\
\hline Feminino & 45 & 70,3 \\
\hline \multicolumn{3}{|l|}{ Estado civil } \\
\hline Casado & 19 & 30,2 \\
\hline Solteiro & 17 & 27,0 \\
\hline Divorciado/Separado & 15 & 23,8 \\
\hline Viúvo & 12 & 19,0 \\
\hline \multicolumn{3}{|l|}{ Faixa etária } \\
\hline 60 a 70 anos & 46 & 71,9 \\
\hline Mais de 70 anos & 18 & 28,1 \\
\hline \multicolumn{3}{|l|}{ Renda mensal } \\
\hline 1 a 2 SM & 29 & 46,0 \\
\hline 2,1 a 4 SM & 19 & 30,2 \\
\hline Mais de $4 \mathrm{SM}$ & 15 & 23,8 \\
\hline \multicolumn{3}{|l|}{ Escolaridade } \\
\hline 0 a 5 anos & 3 & 4,8 \\
\hline 6 a 14 anos & 24 & 38,1 \\
\hline 15 anos ou mais & 36 & 57,1 \\
\hline \multicolumn{3}{|l|}{ Reprovação escolar } \\
\hline Sim & 25 & 39,7 \\
\hline Não & 38 & 60,3 \\
\hline \multicolumn{3}{|l|}{ Raça } \\
\hline Branca & 34 & 54,0 \\
\hline Negra & 13 & 20,6 \\
\hline Parda & 16 & 25,4 \\
\hline \multicolumn{3}{|l|}{ Pessoas com quem vive } \\
\hline Sozinho & 22 & 35,5 \\
\hline 1 a 2 pessoas & 27 & 43,5 \\
\hline Mais de 3 pessoas & 13 & 21,0 \\
\hline
\end{tabular}

Fonte: Elaboração própria.

Ao comparar as proporções de idosos pertencentes ao GC e GT, em função do perfil sociodemográfico, apresentado na Tabela 2, foi encontrada diferença significativa apenas no sexo $(p=0,001)$ e na raça $(p=0,002)$, indicando que existe uma maior proporção de mulheres no $G C(f=40)$ e de idosos de raça parda no $G T(f=20)$. Não foi encontrada diferença significativa $(p<0,05)$ nas proporções de idosos pertencentes ao GC e GT nas demais variáveis sociodemográficas. 
Tabela 2 - Comparação das proporções de idosos pertencentes ao GC e GT em função do perfil sociodemográfico

\begin{tabular}{|c|c|c|c|}
\hline \multirow{3}{*}{ VARIÁVEIS } & \multicolumn{2}{|c|}{ Grupos } & \multirow{3}{*}{$\mathbf{P}$} \\
\hline & \multirow{2}{*}{$\begin{array}{c}G T(n=44) \\
f(\%)\end{array}$} & \multirow{2}{*}{$\begin{array}{c}G C(n=22) \\
f(\%)\end{array}$} & \\
\hline & & & \\
\hline \multicolumn{4}{|l|}{ Sexo $^{a}$} \\
\hline Masculino & $13(59,1)$ & $6(14,3)$ & \multirow{2}{*}{$0,001 *$} \\
\hline Feminino & $9(40,9)$ & $36(85,7)$ & \\
\hline $\mathrm{X} 2$ & \multicolumn{2}{|c|}{13,885} & \\
\hline \multicolumn{4}{|l|}{ Estado civil $^{\mathrm{a}}$} \\
\hline Casado & $5(23,8)$ & $7(16,7)$ & \multirow{4}{*}{0,934} \\
\hline Solteiro & $2(9,5)$ & & \\
\hline Divorciado/Separado & $9(42,9)$ & $\frac{13(31,0)}{10(23,8)}$ & \\
\hline Viúvo & $5(23,8)$ & $12(28,6)$ & \\
\hline $\mathrm{X} 2$ & \multicolumn{2}{|c|}{0,007} & \\
\hline \multicolumn{4}{|l|}{ Faixa etária $^{a}$} \\
\hline 60 a 70 anos & $15(68,2)$ & $31(73,8)$ & \multirow{2}{*}{0,634} \\
\hline Mais de 70 anos & $7(31,8)$ & $11(26,2)$ & \\
\hline $\mathrm{X} 2$ & \multicolumn{2}{|c|}{0,226} & \\
\hline \multicolumn{4}{|l|}{ Renda mensal $^{a}$} \\
\hline 1 a 2 SM & $8(38,1)$ & $21(50,0)$ & \multirow{3}{*}{0,125} \\
\hline 2,1 a 4 SM & $5(23,8)$ & $14(33,3)$ & \\
\hline Mais de $4 \mathrm{SM}$ & $8(38,1)$ & $7(16,7)$ & \\
\hline $\mathrm{X} 2$ & & & \\
\hline Escolaridade $^{a}$ & & & \\
\hline 0 a 5 anos & $1(4,8)$ & $2(4,8)$ & \\
\hline 6 a 14 anos & $5(23,8)$ & $19(45,2)$ & 0,175 \\
\hline 15 anos ou mais & $15(71,4)$ & $21(50,0)$ & \\
\hline $\mathrm{X} 2$ & & & \\
\hline Reprovação escolar ${ }^{a}$ & & & \\
\hline Sim & $10(47,6)$ & $15(35,7)$ & \\
\hline Não & $11(52,4)$ & $27(64,3)$ & 0,363 \\
\hline $\mathrm{X} 2$ & & & \\
\hline Raça $^{a}$ & & & \\
\hline Branca & $0(0,0)$ & $13(31,0)$ & \\
\hline Negra & $4(19,0)$ & $12(28,6)$ & $0,001 *$ \\
\hline Parda & $17(81,0)$ & $17(40,5)$ & \\
\hline $\mathrm{X} 2$ & & & \\
\hline Pessoas com quem vive & & & \\
\hline Sozinho & $6(28,6)$ & $16(39,0)$ & \\
\hline 1 a 2 pessoas & $9(42,9)$ & $18(43,9)$ & 0,271 \\
\hline Mais de 3 pessoas & $6(28,6)$ & $7(17,1)$ & \\
\hline $\mathrm{X} 2$ & & & \\
\hline
\end{tabular}

*Associação significativa - $p<0,05$ : Teste de Qui-quadrado.

GC: grupo controle; GT: grupo treinamento; SM: salário-mínimo.

Ao comparar o perfil de memória, linguagem e funções executivas entre os grupos (GC e GT) antes (pré-teste) e depois (pós-teste) da intervenção (Tabela 3), não foi encontrada diferença significativa $(p>0,05)$ entre os grupos em nenhum dos momentos. 
Tabela 3 - Comparação do perfil de memória, linguagem e funções executivas pré e pós-teste quanto aos grupos (GC e GT)

\begin{tabular}{|c|c|c|c|c|}
\hline \multirow{2}{*}{ Variáveis } & \multirow{2}{*}{ Momentos } & GC $(n=22)$ & GT $(n=44)$ & \multirow{2}{*}{$\boldsymbol{P}$} \\
\hline & & Md (Q1; Q3) & Md (Q1; Q3) & \\
\hline \multirow{3}{*}{$\begin{array}{l}\text { Tempo de Aplicação } \\
\text { (seg.) }\end{array}$} & Pré & $44,5(35,3 ; 50,8)$ & $42,0(35,0 ; 48,8)$ & 0,438 \\
\hline & Pós & $40,0(33,8 ; 47,8)$ & $40,0(37,3 ; 45,0)$ & 0,621 \\
\hline & & $P=0,519$ & $P=0,686$ & \\
\hline \multirow{3}{*}{ Memória } & Pré & $43,5(37,5 ; 50,8)$ & $48,0(40,3 ; 53,0)$ & 0,317 \\
\hline & Pós & $40,5(33,5 ; 50,0)$ & $42,5(31,5 ; 53,0)$ & 0,544 \\
\hline & & $P=0,626$ & $P=0,342$ & \\
\hline \multirow{3}{*}{ Linguagem } & Pré & $49,0(44,8 ; 51,0)$ & $49,0(47,0 ; 50,8)$ & 0,598 \\
\hline & Pós & $48,0(39,0 ; 50,3)$ & $49,0(43,0 ; 51,0)$ & 0,570 \\
\hline & & $P=0,155$ & $P=0,131$ & \\
\hline \multirow{3}{*}{ Funções Executivas } & Pré & $6,0(4,8 ; 7,3)$ & $6,5(5,0 ; 7,8)$ & 0,524 \\
\hline & Pós & $5,0(3,8 ; 7,0)$ & $5,0(4,0 ; 7,8)$ & 0,262 \\
\hline & & $P=0,099$ & $P=0,113$ & \\
\hline \multirow{3}{*}{ Escore total } & Pré & $162,0(146,8 ; 172,3)$ & $164,5(147,5 ; 174,0)$ & 0,698 \\
\hline & Pós & $151,0(126,8 ; 173,3)$ & $155,0(128,8 ; 174,8)$ & 0,549 \\
\hline & & $P=0,178$ & $P=0,145$ & \\
\hline
\end{tabular}

Fonte: Elaboração própria.

*Diferença Significativa $(\mathrm{p}<0,05)$ - Teste " $U$ " de Mann-Whitney para grupos e teste de Wilcoxon para momentos. GC: grupo controle; GT: grupo treinamento.

Ao analisar a correlação entre o perfil de memória, linguagem e funções executivas dos idosos do GC e GT no momento pré-teste (Tabela 4), verificaram-se as seguintes correlações significativas $(p<0,05)$ : GC) memória com linguagem $(r=0,59)$, funções executivas $(r=0,43)$, escore total $(r=0,87)$ e tempo de aplicação $(r=-0,68)$, linguagem com funções executivas $(r=$ $0,63)$ e escore total $(r=0,80)$, funções executivas com escore total $(r=0,58)$; GT) memória com linguagem $(r=0,31)$, funções executivas $(r=0,40)$ e escore total $(r=0,57)$, linguagem com funções executivas $(r=0,29)$, e escore total com funções executivas $(r=0,35)$ e tempo de aplicação $(r=-0,40)$.

Tabela 4 - Correlação entre o perfil de memória, linguagem e funções executivas dos idosos do GC e GT no momento pré-teste

\begin{tabular}{l|c|c|c|c|c}
\hline \multicolumn{1}{c|}{ GC e GT } & $\mathbf{1}$ & $\mathbf{2}$ & $\mathbf{3}$ & $\mathbf{4}$ & $\mathbf{5}$ \\
\hline 1. Memória & - & $0,59^{*}$ & $0,43^{*}$ & $0,87^{*}$ & $-0,68^{*}$ \\
\hline 2. Linguagem & $0,31^{*}$ & - & $0,63^{*}$ & $0,80^{*}$ & $-0,31$ \\
\hline 3. Funções Executivas & $0,40^{*}$ & 0,26 & - & $0,58^{*}$ & $-0,30$ \\
\hline 4. Escore total & $0,57^{*}$ & 0,29 & $0,35^{*}$ & - & $-0,52^{*}$ \\
\hline 5. Tempo de Aplicação & $-0,15$ & $-0,16$ & $-0,13$ & $-0,40^{*}$ & - \\
\hline
\end{tabular}

Fonte: Elaboração própria.

*Correlação significativa $(\mathrm{p}<0,05)$ - Correlação de Spearman.

GC: grupo controle; GT: grupo treinamento. 
No pós-teste (Tabela 5), verificaram-se as seguintes correlações significativas ( $p<$ $0,05)$ : GC) memória com linguagem $(r=0,81)$, funções executivas $(r=0,73)$ e escore total $(r=$ $0,92)$; linguagem com funções executivas $(r=0,74)$ e escore total $(r=0,92)$; e funções executivas com escore total $(r=0,77)$; GT) memória com linguagem $(r=0,68)$, funções executivas $(r=0,62)$ e escore total $(r=0,797)$, linguagem com funções executivas $(r=0,72)$; e escore total $(r=0,78)$; e escore total com funções executivas $(r=0,71)$. Destaca-se que os coeficientes de correlação foram mais altos tanto no GC quanto no GT, indicando que a relação linear entre as variáveis ficou mais forte em ambos os grupos no pós-teste.

Tabela 5 - Correlação entre o perfil de memória, linguagem e funções executivas dos idosos do GC e GT no momento pós-teste

\begin{tabular}{l|c|c|c|c|c}
\hline \multicolumn{1}{c|}{ GC e GT } & $\mathbf{1}$ & $\mathbf{2}$ & $\mathbf{3}$ & $\mathbf{4}$ & $\mathbf{5}$ \\
\hline 1. Memória & - & $0,81^{*}$ & $0,73^{*}$ & $0,92^{*}$ & $-0,36$ \\
\hline 2. Linguagem & $0,68^{*}$ & - & $0,74^{*}$ & $0,92^{*}$ & $-0,18$ \\
\hline 3. Funções Executivas & $0,62^{*}$ & $0,72^{*}$ & - & $0,77^{*}$ & $-0,30$ \\
\hline 4. Escore total & $0,79^{*}$ & $0,78^{*}$ & $0,71^{*}$ & - & $-0,35$ \\
\hline 5. Tempo de Aplicação & $-0,03$ & $-0,19$ & $-0,12$ & $-0,16$ & - \\
\hline
\end{tabular}

Fonte: Elaboração própria.

*Correlação significativa $(p<0,05)$ - Correlação de Spearman.

GC: grupo controle; GT: grupo treinamento.

\section{DISCUSSÃO}

Diante dos dados encontrados, o que se pode presumir é que as práticas de educação permanente dirigidas ao público idoso escolarizado, em uma perspectiva freireana de Círculo de Cultura, contribuem para a melhoria de desempenho das funções neuropsicológicas e dos tempos de respostas aos desafios diários, pois promovem novos conhecimentos, novas aprendizagens e novas interações na velhice, além de estimularem a autonomia, o pensar crítico e a qualidade de vida.

Segundo Lins (2009), a educação voltada ao idoso brasileiro deve ser transformadora e oferecer ferramentas necessárias a esse sujeito para a sua participação e intervenção nas tomadas de decisões referentes à sua vida, dentro da sociedade, deixando de atuar como um sujeito passivo da ação de outros sobre si e suas necessidades. Ademais, a participação relaciona-se diretamente a uma prática educativa progressista.

O que se reconhece é que o processo de educação permanente do idoso é de 
interação, de intersubjetividade, de ajuste de significados dos sujeitos envolvidos (PALMA; CACHIONI, 2006). Como não se trata apenas de ocupar um tempo livre, mas de atender às demandas e às necessidades educativas e socioculturais dos idosos, um método participativo, interativo, horizontal e dialógico permite ao idoso perceber-se ator do processo e produtor de conteúdos vitais para a autotransformação e a transformação do entorno em que está inserido. O que se pode inferir é que a comunicação, termo caro a Paulo Freire, torna-se, desse modo, característica fundante no processo.

Assim, para conhecer o perfil sociodemográfico dos idosos que procuram práticas educativas na velhice, investigou-se o perfil socioeconômico, de escolarização, idade e origem étnica dos idosos frequentadores da oficina "Diálogos com quem gosta de ler e escrever". No geral, os dados encontrados, apontados nas tabelas anteriores, corroboram as pesquisas de Amodeo, Maria Netto e Fonseca (2010), Massi et al. (2010, 2015), Souza Filho (2011), Souza Filho e Massi (2014), Souza Filho, Massi e Ribas (2014), Torquato, Massi e Santana (2011) quanto ao perfil sociodemográfico do idoso que se interessa por práticas educativas: mulher, branca, aposentada e de classe média.

Quanto às relações de escolaridade e renda mensal com perfil neuropsicológico geral (pré e pós teste) dos participantes dos dois grupos têm-se que o perfil de memória, linguagem e funções executivas entre os grupos antes (pré-teste) e depois (pós-teste) da intervenção (Tabela 3), não apresenta diferença significativa entre eles em nenhum dos momentos. Ao comparar as variáveis do pré para o pós-teste dentro de cada grupo (Tabela 3), também não foi encontrada diferença significativa em nenhuma das variáveis em ambos os grupos.

Para a correlação entre o perfil de memória, linguagem e funções executivas dos idosos do GC e GT no momento pré-teste (Tabela 4), verificou-se as seguintes correlações significativas: no GC) memória com linguagem, funções executivas, escore total e tempo de aplicação, linguagem com funções executivas e escore total, funções executivas com escore total; e no GT) memória com linguagem, funções executivas e escore total, linguagem com funções executivas, e escore total com funções executivas e tempo de aplicação.

O que se pode verificar, a partir da Correlação de Spearman, é que os coeficientes de correlação foram mais altos tanto no GC quanto no GT, indicando que a relação linear entre as variáveis ficou mais forte em ambos os grupos no pós- teste. Assim sendo, infere-se que a prática educativa na velhice pode gerar ganhos significativos à cognição. 


\section{RESULTADOS QUALITATIVOS}

Após a leitura meticulosa de cada produção escrita, procurou-se fazer uma interpretação que possibilitasse revelar conteúdos presentes na produção escrita dos idosos. Para tanto, identificaram-se as seguintes categorias: 1. Significado dos Círculos de Cultura; e 2. Sentimentos que esses sujeitos idosos têm em relação à educação permanente e ao ato educativo em suas vidas. Nesse sentido, a Figura 1 traz os conceitos mais expressivos destacados pelos idosos participantes.

Figura 1 - Síntese das categorias e subcategorias para educação permanente: conceitos extraídos da produção escrita

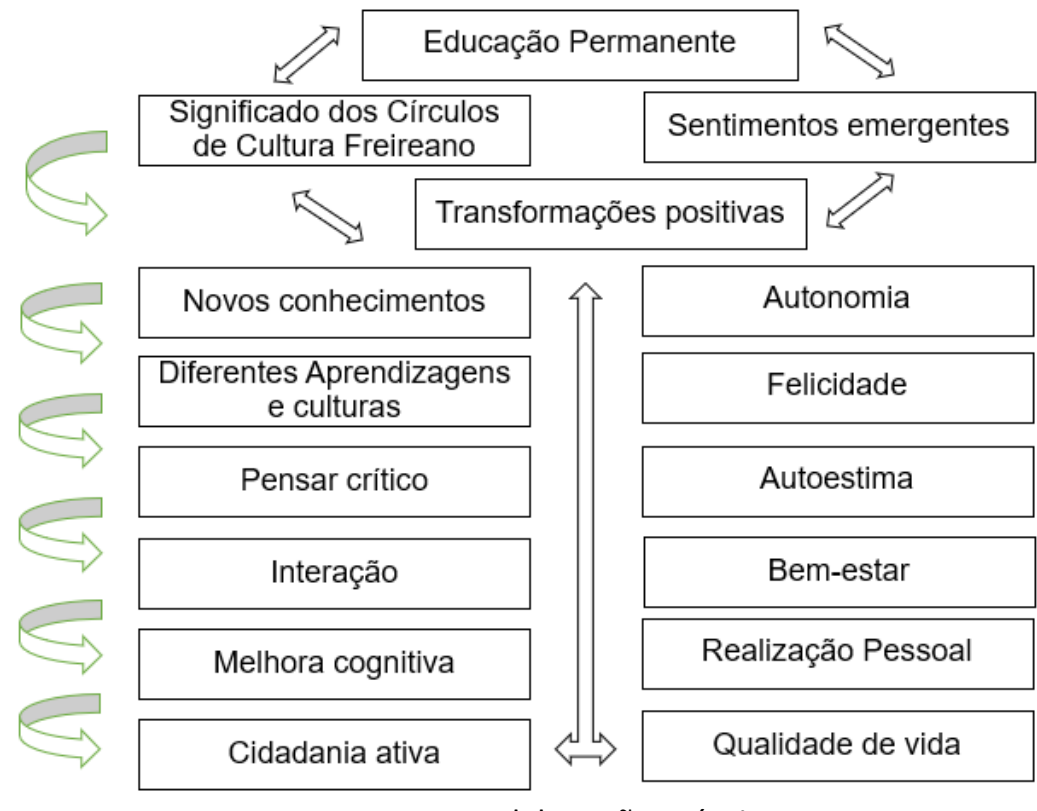

Fonte: Elaboração própria.

Pode-se perceber na Figura 1 que as subcategorias destacadas para ambas as categorias indicam transformações positivas na vida dos idosos participantes da oficina. Das 44 produções escritas analisadas, foi possível apenas extrair significados e sentimentos positivos em relação à educação. Em sua totalidade, os idosos apontaram ganhos e satisfação com os processos de aprendizagem, com a atividade intelectual e com os Círculos de Cultura. Dessa forma, apresentam-se, no Quadro 1, os dados qualitativos, expressos em categorias, subcategorias e trechos de fala para exemplificação.

Quadro 1 - Categorias e subcategorias: definições e exemplos de respostas 


\begin{tabular}{|c|c|}
\hline Categorias e definições & $\begin{array}{c}\text { Subcategorias e exemplos de trechos extraídos das } \\
\text { entrevistas }\end{array}$ \\
\hline \multirow[t]{6}{*}{$\begin{array}{l}\text { Categoria 1: Significado dos círculos de } \\
\text { cultura. } \\
\text { Definição: nesta categoria, estão presentes } \\
\text { os significados atribuídos pelos idosos à } \\
\text { prática de educação, por meio de Círculos } \\
\text { de Cultura, em suas vidas. }\end{array}$} & $\begin{array}{l}\text { Novos conhecimentos: "Participando das aulas, tive a } \\
\text { certeza de que iria aprender muito mais, além da matéria } \\
\text { português, iria fortalecer laços de convívio social, com o } \\
\text { trocar de ideias com tantas pessoas diferentes e com } \\
\text { histórias diferentes, isso só vem mostrar que temos a } \\
\text { necessidade de fazer parte de algo maior" (R. A. N.). }\end{array}$ \\
\hline & $\begin{array}{l}\text { Diferentes aprendizagens e culturas: "É muito } \\
\text { enriquecedor o conhecimento e a convivência com outras } \\
\text { pessoas de idades semelhantes e diferentes. Porém, cada } \\
\text { um com culturas e conhecimentos variados, estilos e } \\
\text { modos de vida diferenciados" (J. D.). }\end{array}$ \\
\hline & $\begin{array}{l}\text { Pensar crítico: "Depois da oficina, me sinto mais à } \\
\text { vontade para falar o que penso sem medo de ser } \\
\text { criticada, isso é muito bom, me sinto mais segura" (I. E. } \\
\text { S.). }\end{array}$ \\
\hline & $\begin{array}{l}\text { Interação: "A troca de experiência com os colegas, fez } \\
\text { toda a diferença; temos a liberdade de fazer perguntas e } \\
\text { tirar dúvidas" (S. A. V). }\end{array}$ \\
\hline & $\begin{array}{l}\text { Melhora cognitiva: "A oficina, conseguiu seu objetivo, ou } \\
\text { seja, o retorno de atividades intelectuais diversas da vida } \\
\text { cotidiana para terceira idade" (G. W. M.); e "O que } \\
\text { aconteceu comigo foi enriquecimento cognitivo e de } \\
\text { relacionamento" (J. L. F). }\end{array}$ \\
\hline & $\begin{array}{l}\text { Cidadania ativa: "É um lugar onde posso ouvir e ser } \\
\text { ouvida" (M. J. B.). }\end{array}$ \\
\hline \multirow{6}{*}{$\begin{array}{l}\text { Categoria 2: Sentimentos que emergem ao } \\
\text { estarem inseridos em um processo de } \\
\text { educação permanente. } \\
\text { Definição: nesta categoria, estão presentes } \\
\text { os sentimentos emergentes nos idosos } \\
\text { durante o ato educativo permanente. }\end{array}$} & $\begin{array}{l}\text { Autonomia: "Essa experiência fez com que eu verificasse } \\
\text { como as pessoas são iguais a mim e ao mesmo tempo são } \\
\text { diferentes" (I. S. A.). }\end{array}$ \\
\hline & $\begin{array}{l}\text { Felicidade: "Me sinto feliz por agora fazer parte de um } \\
\text { grupo de pessoas que se parecem comigo" (M. J. B.). }\end{array}$ \\
\hline & $\begin{array}{l}\text { Autoestima: "A oficina elevou minha autoestima, tanto } \\
\text { em conhecimento como em saúde" (E. M. P); e "Todos } \\
\text { temos os mesmos objetivos, adquirir conhecimentos e se } \\
\text { sentir útil" (N. N. Q.). }\end{array}$ \\
\hline & $\begin{array}{l}\text { Bem-estar: "Me sinto bem, nos poucos encontros que } \\
\text { participei, sinto que minha mente está bem melhor e } \\
\text { estou cheia de ideias para ofuturo" (J. S. S.). }\end{array}$ \\
\hline & $\begin{array}{l}\text { Realização Pessoal: "Percebi também no convívio, com } \\
\text { aqueles de igual condição, que as palavras envelhecem } \\
\text { dentro de cada um, não é só o corpo [...] Existe um } \\
\text { caminho longo para seguir" (G. W. M.). }\end{array}$ \\
\hline & $\begin{array}{l}\text { Qualidade de Vida: "Foi bastante útil para mim, forçou- } \\
\text { me a pensar e a escrever sobre os temas propostos" (J. B. } \\
\text { C.); e "Em casa fico fazendo bordados, costuras e } \\
\text { artesanatos, não estudo nada. A terceira idade precisa } \\
\text { mais de aulas com esse movimento de ler, discutir e } \\
\text { escrever" (M. Z.). }\end{array}$ \\
\hline
\end{tabular}

Fonte: Elaboração própria.

\section{DISCUSSÃO}


As propostas dos Círculos de Cultura pautaram-se nos pressupostos freireanos, em que os temas geradores eram a base para o diálogo nos encontros. Sobre a organização da sala de aula, conforme registrado por um idoso participante: "[...] na nossa sala é formado um círculo que facilita muito os diálogos sobre um tema em discussão na mídia ou de algum livro. Nesse círculo, ficamos sempre de frente a todos o que facilita muito a amizade uns com os outros" (D. C.).

Os temas geradores foram: política, sexualidade, trabalho, estética na velhice, entre outros, partindo sempre das experiências individuais e da leitura de mundo que cada idoso carrega. De acordo com outro idoso frequentador da oficina, "[...] foram encontros bons, criativos, leves e sem o compromisso da escola, apenas desenvolvemos o que estava adormecido" (C. V. B).

A ideia era gerar uma educação problematizadora, respondendo à essência do ser da consciência, que é sua intencionalidade, negando os comunicados, na construção de saberes coletivos (FREIRE, 1997). Desse modo, para alguns dos idosos "[...] foi uma experiência prazerosa e enriquecedora e em certo momento fez com que [...] esquecesse a timidez $e$ falasse sobre algumas experiências próprias" (A. S. S.). Para a maioria deles, ter vez e voz foi fundamental para manterem-se ativos na proposta de educação, como pode ser percebido na fala de um dos idosos: "[...] gostei demais da oficina, dos temas e das opiniões dos colegas sobre os assuntos e nós podíamos dar sugestões, concordando ou discordando e também acrescentando o que achávamos sobre os temas" (A. A. F.).

Assim, educar não se restringe apenas a um período de tempo e de vida específicos, uma vez que possuímos a capacidade de aprender ao longo de toda a nossa vida. Essa mesma capacidade ainda não está limitada à fase ou ao ambiente escolar, mas está junto às relações sociais com o meio em que se vive e que representam importantes estímulos à vida em sociedade. Educa-se, portanto, em todos os tempos e espaços, em suas relações com sujeitos e objetos distintos.

Ressalte-se ainda que de uma perspectiva de curso de vida, os programas educacionais na velhice são essenciais para o bem-estar social, físico e para o desenvolvimento pessoal (CACHIONI, 1999, 2002, 2005, 2006) do idoso. Uma das participantes reconhece que: "Todos nós temos uma grande mala cultural, que podemos abrir para repartir o que sabemos com os outros, mas também podemos completar essa 
mala, com a bagagem que outras pessoas podem nos trazer. Isso nos completa e faz mais felizes." (M. A. M.).

A educação requer do sujeito o desenvolvimento de atitudes do aprender para o autoconhecimento, a comunicação, a empatia, a resolução de conflitos e para a realização de tarefas, utilizando-se de uma bagagem de conhecimentos teóricopráticos construídos em seu trânsito de vida, de modo a tomar para si uma consciência crítica do mundo e das práticas sociais. Destaca-se, dos idosos, falas como: "Adoro estar aqui, a interação e os diálogos são remédios para alguns de nós" (M. A. A. R.); "Satisfação total em aprender mais" (D. C.); "Acredito ter atingido os objetivos do círculo, pois me sinto ainda mais capaz para lidar com o lado social" (C. V. B.); "Tive muito êxito, porque fiz novas amizades, discutimos sobre os temas lidos nos livros, o que trouxe muita informação nova" (O. V. S.); e "No decorrer da oficina, percebi o quanto não estava familiarizado com a atividade proposta" (G. W. M.).

Pasqualotti e Portella (2005) mostram que, na velhice, os momentos de trocas de experiências, mais do que um processo de ensino e de aprendizagem, atuam como elementos estimuladores da autoestima. Assim, um ambiente acolhedor conduz os idosos a sentirem-se bem consigo mesmos. A razão não é difícil de ser identificada, pois os idosos estão movidos pelo desejo de "partilha" e de "pertencer"; quando partilham as experiências, se sentem importantes para si mesmos e pertencentes ao grupo. É o que se nota neste depoimento: "Minha experiência em participar destes encontros, com todos, é muito gratificante" (M. Z.).

Espaços educativos destinados a idosos não são apenas possibilidades, mas podem ser a concretização de uma realidade que necessita ser plenamente respeitada para viver a velhice de forma digna, à medida que possam usufruir de uma formação integral e humanizadora. Desse modo, o ato educativo exerce-se sobre os sujeitos ou grupo de sujeitos, "[...] em vista de atingir uma modificação profunda, tal como novas forças vivas nascem nos sujeitos e estes se tornam eles mesmos elementos ativos desta ação exercida sobre eles" (NASSIF, 1980, p. 215). Assim, como registrado na fala dos idosos: "Os temas só reforçam a importância da educação e que nunca é tarde para aprender" (A. S. S.); e "Esta oficina proporciona adquirir novos conhecimentos, conhecer novos colegas da terceira idade, novos professores e monitores e nos enriquece culturalmente" (A. A. F.). 
O ato educativo é uma atividade que gera cultura intelectual, em paralelo à existência do próprio ser (NÓVOA, 1999, p. 69). Percebe-se nos idosos que a educação permanente potencializa as atitudes do aprender e o bem-estar individual, além de oferecer a manutenção das variedades e especialidades das capacidades requeridas para se viver em sociedades que sofrem com rápidas e profundas transformações (PALMA; CACHIONI, 2006), ressignificando suas vidas e produzindo novos e positivos sentidos. Percebe-se esse aspecto nas seguintes falas: "Sou um ser diferente de quando iniciei, sou mais tolerante e tenho um conhecimento maior" (J. L. f.); "Abriu muitas portas para que eu possa aprender cada dia mais" (M. A. L. N.); e "Aprendi muito na sala de aula para usar na vida cotidiana" (J. N. S.).

\section{CONSIDERAÇÕES FINAIS}

Diante dos dados quantitativos, o que se percebe é que não há uma grande diferença no perfil dos idosos dos dois grupos (GC e GT); ambos são parecidos em perfil sociodemográfico e perfil neuropsicológico, encontrando-se a diferença no sexo (mais mulheres - GC) e na etnia (parda - GT). Outrossim, a relação entre o desempenho nos testes de linguagem, memória e funções executivas do NEUPSILIN, com o escore total do teste e do seu tempo de aplicação, já existia entre as variáveis essas relações no momento do pré-teste e no pós- teste, visto que apenas se fortaleceram. Dito de outro modo, a relação estatística entre as variáveis no momento do pré-teste é proporcional nos dois grupos. Nesse caso, há uma relação direta entre a pontuação no desempenho dos testes de linguagem, de memória e das funções executivas com o escore total do NEUPSILIN e o tempo de aplicação do teste. Já no momento do pós-teste, elas se fortalecem, uma vez que são inversamente proporcionais, indicado pelos valores positivos das varáveis. Revela, ainda, que o tempo de aplicação é proporcional aos anos de escolaridade, à renda e ao desempenho dos domínios cognitivos: memória, linguagem e funções executivas, tanto no GC quanto no GT. Logo, quanto maior for a oportunidade de desenvolver a melhoria da qualidade dos três domínios investigados pelo teste, menor é o tempo de aplicação, apontando, dessa forma, para os ganhos neuropsicológicos ao inserir idosos em programas educativos.

Dos dados qualitativos, compreende-se que a prática de educação permanente de idosos promoveu mudanças positivas na vida de idosos frequentadores dessas oficinas. Com 
isso, denota-se a urgência da necessidade de relatar práticas educativas, especialmente propostas pautadas no Círculo de Cultura freireano, e relacioná-las aos benefícios percebidos pelos idosos. Dessa maneira, renova-se a esperança de que a sociedade, em médio e longo prazo, mobilize-se de forma expressiva, na promoção dos direitos básicos que cada cidadão tem de viver a velhice com qualidade.

Por fim, guardadas as limitações deste estudo, foi possível notar que o estabelecimento de um diálogo entre a Gerontologia e a Educação, por meio de uma ação educativa, trouxe pistas para futuras pesquisas na perspectiva de uma pedagogia freireana que tem no círculo de cultura um caminho que pode ser um instrumento a mais na educação de pessoas idosas.

\section{REFERÊNCIAS}

AMODEO, M.T.; MARIA NETTO, T.; FONSECA, R.P. Desenvolvimento de programas de estimulação cognitiva para adultos idosos: modalidades da Literatura e da Neuropsicologia. Letras de Hoje. Porto Alegre. v. 45, n. 3, jul./set. 2010. p. 54-64.

BARDIN, L. Análise de conteúdo. São Paulo: Edições 70, 2011.

CACHIONI, M. Formação profissional, motivos e crenças relativas à velhice $e$ ao desenvolvimento pessoal entre professores de universidades da terceira idade. Tese de Doutorado em Educação. Unicamp, Campinas: 2002.

CACHIONI, M. Envelhecimento bem-sucedido e a participação numa Universidade para a Terceira Idade: a experiência dos alunos da Universidade São Francisco. Dissertação de Mestrado em Educação. Unicamp, Campinas: 1998.

CACHIONI, M. Universidade da Terceira Idade. In: NÉRI, A. L. (Org.), Palavras-chave em Gerontologia. Campinas: Alínea, 2005, p. 207-210.

CACHIONI, M. Universidades da terceira idade: das origens à experiência brasileira. In: NÉRI, A.L. e DEBERT, A.G. (Org.), Velhice e Sociedade. Campinas: Papirus, 1999, p. 141-178.

CACHIONI, M.; NERI, A.L. Educação e gerontologia: desafios e oportunidades. Revista Brasileira De Ciências Do Envelhecimento Humano. Passo Fundo. v. 1, n. 1, maio 2006. DOI: https://doi.org/10.5335/rbceh.2012.49

CACHIONI, M.; NERI, A.L. Educação e velhice bem-sucedida no contexto das universidades da terceira idade. In: NÉRI, A.L.; YASSUDA, M.S.; CACHIONI, M. (Orgs.), Velhice bem-sucedida: aspectos afetivos e cognitivos. Campinas: Papirus, 2008, p. 29-50. 
FREIRE, P. Pedagogia do oprimido. 17. ed. Rio de Janeiro: Paz e Terra, 1987.

FREIRE, P. Professora sim, tia não: cartas a quem ousa ensinar. São Paulo: Olho d'água, 1997.

LINS, T. Em busca do gerontólogo educacional brasileiro: uma construção do modelo do gerontólogo educacional a ser aplicado no Brasil. 2009. Tese de Doutorado em Educação. Universidade de Salamanca, Salamanca: 2009.

MASSI, G. et al. Linguagem e envelhecimento: práticas de escrita autobiográfica junto a idosos. CEFAC. São Paulo. v. 17, n. 6, nov./dez. 2015. p. 2065-2071. DOI: https://doi.org/10.1590/1982-021620151764615

MASSI, G. et al. Práticas de letramento no processo de envelhecimento. Revista Brasileira de Geriatria e Gerontologia. Rio de Janeiro. v. 13, n. 1, 2010. p. 59-71. DOI: https://doi.org/10.1590/S1809-98232010000100007

NASSIF, R. Pedagogia de nosso tempo. 5. ed. Rio de Janeiro: Vozes, 1980.

NÓVOA, A. Profissão professor. Porto: Porto Editora, 1999.

PALMA, L.S. CACHIONI, M. Educação permanente: perspectiva para o trabalho educacional com o adulto maduro e com o idoso. In: FREITAS, E.V. (Org.), Tratado de Geriatria e Gerontologia. 2. Ed. Rio de Janeiro: Guanabara Koogan, 2006, p. 1101-1109.

PASQUALOTTI, A.; PORTELLA, M.R. Ambiente Vivencer: experimentação de ambiente informatizado para a construção de relações socioafetivas na velhice. Revista Brasileira de Ciências do Envelhecimento Humano. Passo Fundo. v. 2, n. 1, jan./jun. 2005. p. 43-60. DOI: https://doi.org/10.5335/rbceh.2012.25

SOUZA FILHO, P.P.S. Condições de letramento no processo de envelhecimento: uma análise junto a idosos com mais de 65 anos. Tese de Doutorado em Distúrbios da Comunicação. UTP, Curitiba: 2011.

SOUZA FILHO, P.P.S; MASSI, G.A.A. Letramento de idosos brasileiros acima de 65 anos. Distúrbios da Comunicação. São Paulo. v. 26, n. 2, jun. 2014. p. 267-276.

SOUZA FILHO, P.P.S; MASSI, G. A. A.; RIBAS, A. Escolarização e seus efeitos no letramento de idosos acima de 65 anos. Revista Brasileira de Geriatria e Gerontologia. Rio de Janeiro. v. 17, n. 3, 2014. p. 589-600. DOI: https://doi.org/10.1590/1809-9823.2014.13117

TORQUATO, R.; MASSI, G.; SANTANA, A.P. Envelhecimento e Letramento: A Leitura e a Escrita na Perspectiva de Pessoas com Mais de 60 Anos de Idade. Psicologia: Reflexão e Crítica. Porto Alegre. v. 24, n. 1, , 2011. p. 89-98. DOI: https://doi.org/10.1590/S0102-79722011000100011

Recebido em 19 de dezembro de 2020.

Aprovado em 05 de junho de 2021.

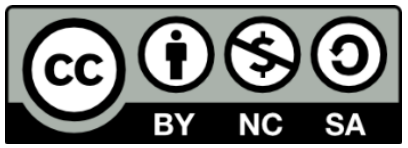

